Check for updates

Cite this: RSC Adv., 2019, 9, 27749

\title{
Diaminophosphinoboranes: effective reagents for phosphinoboration of $\mathrm{CO}_{2}^{\dagger}$
}

\author{
Natalia Szynkiewicz, (D) Anna Ordyszewska, (D) Jarosław Chojnacki (D) \\ and Rafał Grubba (D) *
}

Received 23rd August 2019

Accepted 27th August 2019

The monomeric diaminophosphinoboranes readily react with $\mathrm{CO}_{2}$ under mild conditions to cleanly form products of the general formula $\mathrm{R}_{2} \mathrm{P}-\mathrm{C}(=\mathrm{O})-\mathrm{O}-\mathrm{B}\left(\mathrm{NR}_{2}^{\prime}\right)_{2}$ in the absence of a catalyst. The isolated products from the $\mathrm{CO}_{2}$-phosphinoboration were fully characterized by NMR spectroscopy, IR spectroscopy, and X-ray diffraction. The mechanism of $\mathrm{CO}_{2}$ phosphinoboration with diaminophosphinoboranes was elucidated by DFT calculations.

rsc.li/rsc-advances

\section{Introduction}

Increasingly stringent environmental standards are prompting us to look for clean and efficient methods for the synthesis of organic compounds. In recent years, much attention has been focused on reactions employing simple, nonmetallic P,Bbased $^{1-6}$ systems that can activate waste gases such as $\mathrm{CO},{ }^{7,8}$ $\mathrm{CO}_{2},{ }^{9-13} \mathrm{NO}_{x},{ }^{10,14} \mathrm{SO}_{2},{ }^{14,15}$ or even $\mathrm{H}_{2}{ }^{5,9,16-19}$ These metal-free reactions not only involve easily accessible and inexpensive gaseous reagents as the feedstock but also enable the straightforward and efficient synthesis of organic compounds through the functionalization of small inorganic molecules. ${ }^{20-26}$ The resulting products can be directly used as substrates for the synthesis of more complex systems that are difficult or impossible to obtain by other means.

The largest portion of reports are those devoted to $\mathrm{CO}_{2}{ }^{11,12,17,22,27}$ and its incorporation into organic molecules under mild conditions. While highly nucleophilic phosphines form stable adducts with $\mathrm{CO}_{2},{ }^{11}$ boranes capture $\mathrm{CO}_{2}$ only in the presence of a Lewis base ${ }^{12}$ that can act as either a stoichiometric $^{4,27}$ or catalytic ${ }^{23}$ coreagent or as the site of the ambiphilic molecule. One of the most common systems of this kind is frustrated Lewis pairs (FLPs), involving inter- or intramolecular combinations of sterically encumbered Lewis acids and bases that cannot quench each other. ${ }^{18}$ In the reaction of P,B-based FLPs with $\mathrm{CO}_{2}$, the synergistic interactions of the P-center with a carbon atom and the B-center with an oxygen atom lead to the formation of $\mathrm{P}-\mathrm{C}$ and $\mathrm{B}-\mathrm{O}$ bonds, respectively, giving zwitterionic products with the formula $\mathrm{R}_{3} \mathrm{P}-\mathrm{C}(\mathrm{O})-\mathrm{O}-\mathrm{BR}_{3}^{\prime}{ }^{27}$

Department of Inorganic Chemistry, Faculty of Chemistry, Gdańsk University of Technology, G. Narutowicza St. 11/12. PL-80-233, Gdansk, Poland. E-mail: rafal. grubba@pg.edu.pl

$\dagger$ Electronic supplementary information (ESI) available: Experimental, crystallographic, spectroscopic and computational details. CCDC 1906496 and 1906498-1906500. For ESI and crystallographic data in CIF or other electronic format see DOI: 10.1039/c9ra06638a
In the vast majority of FLPs, the presence of highly electronwithdrawing substituents to increase the acidity of the $\mathrm{B}$ atom is crucial for efficient $\mathrm{CO}_{2}$ fixation. However, it was shown that geminal FLPs, in which the donor and acceptor sites are separated by one atom, can activate $\mathrm{CO}_{2}$ despite the mild Lewis acidity of the boron center. ${ }^{28,29}$

These reports inspired us to go one step further and investigate whether systems in which the $\mathrm{B}$ atom is directly bound to the phosphorus atom also activate $\mathrm{CO}_{2}$. Hence, we focused on monomeric phosphinoboranes, which are another type of ambiphilic P,B-based molecules. ${ }^{30,31} \mathrm{~A}$ recent very comprehensive review ${ }^{31}$ by Pringle et al. classifies these species containing a single $\mathrm{P}-\mathrm{B}$ bond with a pyramidal $\mathrm{P}$ atom and the general formula $\mathrm{R}_{2} \mathrm{P}_{-} \mathrm{BR}_{2}$ as borylphosphines ${ }^{30,32,33}$ and those with a double $\mathrm{P}=\mathrm{B}$ bond and trigonal planar $\mathrm{P}$ atom and the general formula $\mathrm{R}_{2} \mathrm{P}=\mathrm{BR}_{2}^{\prime}$ as phosphinoboranes. ${ }^{34-36}$ Notably, we found that there are a limited number of reports on the reactivity of $\mathrm{P}-\mathrm{B}$ bond systems towards small molecules. Phosphinoboranes $\mathrm{R}_{2} \mathrm{P}=\mathrm{B}\left(\mathrm{C}_{6} \mathrm{~F}_{5}\right)_{2}(\mathrm{R}=t \mathrm{Bu}, \mathrm{Cy})$ exhibit FLP-like reactivity towards $\mathrm{H}_{2}{ }^{34,37}$ The Westcott group explored the chemistry of phosphinoboronate ester $\mathrm{Ph}_{2} \mathrm{P}-\mathrm{Bpin}^{38}$ (pin $=1,2-\mathrm{O}_{2} \mathrm{C}_{2} \mathrm{Me}_{4}$ ), which effectively functionalizes a wide variety of heterorganic systems, such as carbonyls, ${ }^{38,39} \mathrm{~N}$-heterocycles, ${ }^{40}$ aldimines, ${ }^{38,39}$ carbodiimides ${ }^{41}$ and isocyanates. ${ }^{41}$ Very recently Wescott and Stephan tested reactivity of $\mathrm{R}_{2} \mathrm{PBpin}(\mathrm{R}=\mathrm{Ph}, t \mathrm{Bu}), \mathrm{R}_{2} \mathrm{PBMes}_{2}(\mathrm{R}=\mathrm{Ph}$, $t \mathrm{Bu})$, and $\mathrm{R}_{2} \mathrm{PBcat}\left(\mathrm{R}=\mathrm{Ph}, t \mathrm{Bu}\right.$, Mes) towards $\mathrm{CO}_{2}$, where the reactions with the first and the second group of phosphinoboranes gave $\mathrm{R}_{2} \mathrm{PCO}_{2}$ Bpin and $\mathrm{R}_{2} \mathrm{PCO}_{2} \mathrm{BMes}$ respectively, whereas the reaction involving $\mathrm{R}_{2} \mathrm{PBcat}$ yielded $\left(\mathrm{R}_{2} \mathrm{P}\right)_{2} \mathrm{CO}$ and $\mathrm{O}(\text { Bcat })_{2} \cdot{ }^{42}$

As a part of our research program on applying P-P bond systems to the activation of small molecules, we recently reported the first example of $\mathrm{CO}_{2}$ diphosphination by unsymmetrical diphosphanes ${ }^{43}$ in the presence of $\mathrm{BPh}_{3}$. Herein, a weak Lewis acid catalyzes the insertion of $\mathrm{CO}_{2}$ into the $\mathrm{P}-\mathrm{P}$ 


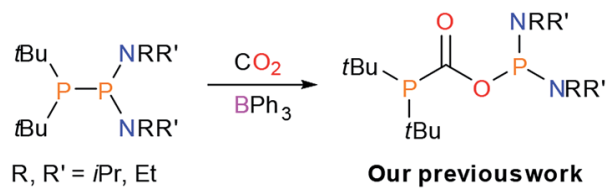

Scheme 1 Diphosphination of $\mathrm{CO}_{2}$ by unsymmetrical diphosphanes. ${ }^{44}$

bond of the Lewis basic component with the formation of $\mathrm{P}-\mathrm{C}$ and $\mathrm{P}-\mathrm{O}$ bonds in a reversible manner (Scheme 1). ${ }^{44}$

Our studies revealed that the presence of long and polarized $\mathrm{P}-\mathrm{P}$ bonds is crucial for the activation of $\mathrm{CO}_{2}$ by diphosphanes. Herein, we decided to apply this synthetic approach to trivalent phosphorus and boron compounds with direct $\mathrm{P}-\mathrm{B}$ bonds.

\section{Results and discussion}

To this end, we designed and synthesized a series of new phosphinoboranes 1-3, which are structural analogs of unsymmetrical diphosphanes where one $\mathrm{P}$ atom has been replaced by a $\mathrm{B}$ atom (Scheme 2). The first step of the synthesis was the reaction of $\mathrm{BBr}_{3}$ with a four-fold excess of $\mathrm{iPr}_{2} \mathrm{NH}$ in petroleum ether with the elimination of an ammonium salt and formation of the bromo(diamino)borane. Then, the obtained product was used in the equimolar reaction with the corresponding lithium phosphide $\left(\mathrm{RR}^{\prime} \mathrm{PLi}\right)$ in toluene at $-50{ }^{\circ} \mathrm{C}$. Diaminophosphinoboranes 1-3 were isolated by removal of the $\mathrm{LiBr}$ followed by evaporation of the solvent, giving analytically pure products in high yields (83-88\%).

The ${ }^{31} \mathrm{P}\left\{{ }^{1} \mathrm{H}\right\}$ NMR spectra of $\mathbf{1}, \mathbf{2}$ and $\mathbf{3}$ show broad singlets at $-8.0 \mathrm{ppm},-26.2 \mathrm{ppm}$ and $-36.1 \mathrm{ppm}$, respectively. The upfield resonances in the ${ }^{31} \mathrm{P}\left\{{ }^{1} \mathrm{H}\right\}$ NMR spectra of 1-3 indicate a lack of significant $\mathrm{P}-\mathrm{B} \pi$-interaction within these molecules. The ${ }^{11} \mathrm{~B}$ NMR spectra of 1-3 each exhibit only one broad singlet (39.5 ppm (1); 40.4 ppm (2); and 38.8 ppm (3)) at values typical for trivalent $\mathrm{R}_{2} \mathrm{P}-\mathrm{BR}_{2}^{\prime}$ species. ${ }^{30,31}$ The broadness of the signals in the ${ }^{31} \mathrm{P}\left\{{ }^{1} \mathrm{H}\right\}$ and ${ }^{11} \mathrm{~B}$ spectra can be explained by the quadrupolar nature of boron. Moreover, the ${ }^{1} J_{\mathrm{P}-\mathrm{B}}$ coupling is not visible likely because of the small value of this coupling constant and mentioned broadness of the signals. The crystallization from petroleum ether at $-20{ }^{\circ} \mathrm{C}$ resulted in colorless crystals of 2 and 3. The X-ray structures of 2 and 3 are presented in Fig. 1. The most characteristic structural features of 2 and 3 are the planar geometry of the $\mathrm{N}$ and $\mathrm{B}$ atoms with the sum of the angles being close to $360^{\circ}$, the pyramidal geometry of the $\mathrm{P}$ atom (sum $323.8^{\circ}(2) ; 316.95$ (3)) and the very long B-P distance (1.983(2) A (2); 1.984(1) A (3)). The B-P bond lengths in 2 and 3 are among the longest distances reported for phosphinoboranes, ${ }^{30,31}$ and they are even slightly longer than the sum of the single covalent bond radii of $\mathrm{B}$ and $\mathrm{P}(1.96 \AA) .{ }^{45}$

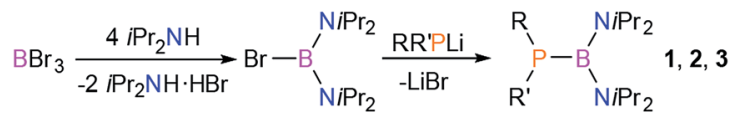

$$
\begin{aligned}
& \text { 1: } R_{1}, R^{\prime}=t B u \quad 2: R=t B u, R^{\prime}=P h \quad 3: R, R^{\prime}=P h
\end{aligned}
$$

Scheme 2 Synthesis of diaminophosphinoboranes 1-3.
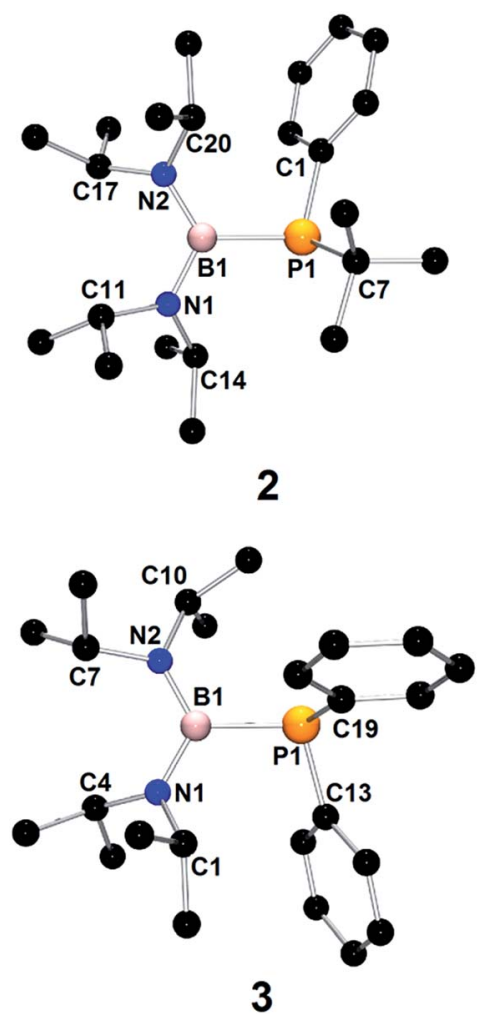

Fig. 1 Molecular structures of 2 and 3.

Moreover, the shortening of the B-N bonds in 2 and 3 to B-N distances in the range of 1.425(1)-1.442(3) A (sum of the single covalent bond radii of $\mathrm{B}$ and $\mathrm{N}$ : $1.56 \AA$; sum of the double covalent bond radii for $\mathrm{B}$ and $\mathrm{N}$ : $1.38 \AA$ ) was observed. ${ }^{45,46}$ This feature, together with the planar geometry of the $\mathrm{N}$ atom, indicates significant $\mathrm{B}-\mathrm{N} \pi$-bonding. NBO analysis of these species provided further insight into the electronic structures of 1-3. The strong interaction between the lone pairs on the $\mathrm{N}$ atoms and the formally empty p-orbital of the $\mathrm{B}$ atom resulting from the formation of $\mathrm{B}-\mathrm{N} \pi$-bonds is clearly visible. Otherwise, donor-acceptor interactions between the $\mathrm{P}$ and $\mathrm{B}$ centers are very weak. Hence, the lone pair on the $\mathrm{P}$ atom is accessible for reactions with electrophilic compounds. The nucleophilic and electrophilic properties of 1-3 were studied by analysis of the condensed Fukui functions. In general, 1-3 have strong nucleophilic character with the nucleophilicity centered at the $\mathrm{P}$ atom. The nucleophilicity of the diaminophosphinoboranes increases in the order $\mathbf{3}<\mathbf{2}<\mathbf{1}$, where the values of $f_{\mathrm{N}}$ for the $\mathrm{P}$ atoms are $0.175,0.198$ and 0.277 , respectively. Interestingly, boron is neither a nucleophilic nor an electrophilic center; the values of both the $f_{\mathrm{N}}$ and $f_{\mathrm{E}}$ Fukui functions are close to zero. Taking into account the results of all the structural and NBO analyses, 1-3 can be described as nucleophilic borylphosphinelike species.

Next, we studied the reactivity of diaminophosphinoboranes 1-3 towards $\mathrm{CO}_{2}$. The reactions of 1,2 or 3 with $\mathrm{CO}_{2}$ (1 atm) at room temperature in toluene resulted in the formation of phosphinoboration products 1a, 2a and 3a, respectively (Scheme 3). The reaction progress was monitored by ${ }^{31} \mathrm{P}\left\{{ }^{1} \mathrm{H}\right\}$ 


$$
\begin{aligned}
\mathbf{1 , 2 , 3} & \underset{\mathrm{R}^{\prime}}{\text { 1, 1a: } \mathrm{R}, \mathrm{R}^{\prime}=t \mathrm{Bu}} \quad \mathbf{2 , 2 a}: \mathrm{R}=t \mathrm{Bu}, \mathrm{R}^{\prime}=\mathrm{Ph} \quad \mathbf{3}, \mathbf{3 a}: \mathrm{R}^{\prime} \mathrm{R}^{\prime}=\mathrm{Ph}
\end{aligned}
$$

Scheme 3 Phosphinoboration of $\mathrm{CO}_{2}$.

and ${ }^{11} \mathrm{~B}$ NMR spectroscopy. The complete conversions of 1 into 1a and 2 into 2 a took 3 hours. In contrast to experiments involving 1 and 2, the reaction of less nucleophilic 3 with $\mathrm{CO}_{2}$ is much slower and was complete after 65 days.

The analytically pure 1a, 2a, and $\mathbf{3 a}$ were isolated in high yields (87-94\%) by evaporation of the solvent as colorless oils solidified below $-20{ }^{\circ} \mathrm{C}$. The ${ }^{31} \mathrm{P}\left\{{ }^{1} \mathrm{H}\right\}$ spectra of $\mathbf{1 a}, \mathbf{2 a}$ and $\mathbf{3 a}$ exhibit sharp singlets at $52.4 \mathrm{ppm}, 23.5$ and $-1.0 \mathrm{ppm}$, respectively. The signals are strongly downfield shifted in comparison to the corresponding resonance of the parent diaminophosphinoboranes, indicating a change in the coordination environment of the $\mathrm{P}$ atom. 1a, 2a, and 3a have very similar ${ }^{11} \mathrm{~B}$ NMR spectra, which show one resonance at a shift of approximately 27 ppm. Furthermore, the ${ }^{13} \mathrm{C}\left\{{ }^{1} \mathrm{H}\right\}$ spectra of the reaction products show a downfield doublet in the range of 180.2-177.9 ppm with ${ }^{1} J_{\mathrm{PC}}(30.9-7.3 \mathrm{~Hz})$. Notably, the ${ }^{31} \mathrm{P}\left\{{ }^{1} \mathrm{H}\right\}$ and ${ }^{13} \mathrm{C}\left\{{ }^{1} \mathrm{H}\right\}$ NMR data of $\mathbf{3 a}$ are very similar to those reported for $\mathrm{Ph}_{2} \mathrm{P}-\mathrm{C}(\mathrm{O})-\mathrm{O}-\mathrm{Bpin} .{ }^{41}$ Moreover, the IR data for 1a and $\mathbf{2 a}$ showed absorption bands at $1644 \mathrm{~cm}^{-1}$ and $1664 \mathrm{~cm}^{-1}$, respectively, which are very characteristic for carbonyl groups.

X-ray diffraction studies of $\mathbf{1 a}$ and 2a unambiguously confirmed that the $\mathrm{CO}_{2}$ molecule is incorporated between the $\mathrm{B}$ and $\mathrm{P}$ atoms (Fig. 2). The X-ray structures of $\mathbf{1 a}$ and 2a are very similar and will be discussed collectively. The $\mathrm{CO}_{2}$ moiety is bound to the phosphanyl group via a carbon atom, whereas one oxygen atom links this moiety with the boryl group. In comparison to parent compounds $\mathbf{1}$ and 2, the planar geometries of the $\mathrm{B}$ and $\mathrm{N}$ atoms and the pyramidal geometry of the $\mathrm{P}$ atom are retained. The geometry of $\mathrm{C} 1$ is also planar. The P1-C1

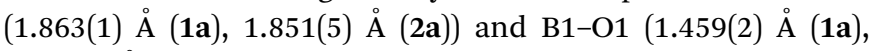
$1.452(6) \AA$ (2a)) bonds values are consistent with single covalent bonds. ${ }^{45}$ The $\mathrm{P} 1-\mathrm{C} 1$ distances in $\mathbf{1 a}$ and $2 \mathrm{a}$ are very similar to corresponding bond distances in $\mathrm{Ph}_{2} \mathrm{PCO}_{2} \mathrm{Bpin}$ and $\mathrm{Ph}_{2} \mathrm{PCO}_{2}$ $\mathrm{BMes}_{2}$, however B1-O1 bond lengths in $1 \mathrm{a}$ and $2 \mathrm{a}$ are about 0.05 A longer than in mentioned compounds. ${ }^{42}$ The C1-O1 (1.345(2)

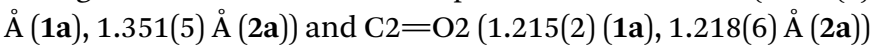
bond distances are very similar to those observed for carboxylic esters $\left(\sim 1.33-1.41 \AA\right.$ and $\sim 1.19-1.20 \AA$, respectively). ${ }^{47}$ The B-N bond lengths in 1a and $2 \mathrm{a}$ are in the range of 1.408(1)-1.438(2) $\AA$ and are slightly shorter than the corresponding distances in parent species $\mathbf{1}$ and 2 . The structures of $\mathbf{1 a}$ and $\mathbf{2 a}$ differ significantly from known structures of $\mathrm{CO}_{2}$ activation products; typically, inter- and intramolecular P,B-based frustrated Lewis pairs form zwitterionic adducts containing tetra-coordinated $\mathrm{P}$ and $\mathrm{B}$ centers. ${ }^{27}$ Compounds $\mathbf{1 a}, \mathbf{2 a}$, and $\mathbf{3 a}$ are stable under argon or vacuum, and even heating these products up to $60{ }^{\circ} \mathrm{C}$ did not regenerate the parent diaminophosphinoboranes.

To investigate the mechanism of $\mathrm{CO}_{2}$ capture by the diaminophosphinoboranes and elucidate the differences in their

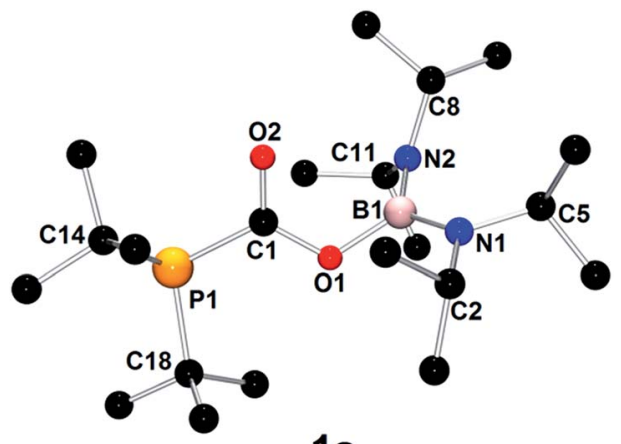

$1 a$

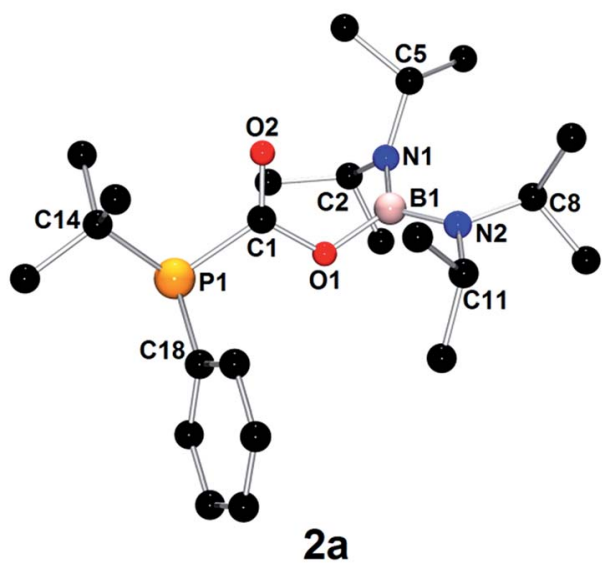

Fig. 2 Molecular structures of $1 \mathrm{a}$ and $2 \mathrm{a}$

reactivities, we carried out DFT calculations. According to the Gibbs energy profile, the insertion of carbon dioxide into the $\mathrm{P}-\mathrm{B}$ bond of $\mathbf{1}$ proceeds via a simple two-step mechanism (Fig. 3).

The reaction starts with a nucleophilic attack of $\mathrm{P}$ on the electrophilic $\mathbf{C O}_{2}$ atom. Upon attachment of $\mathbf{C}$ to the $\mathbf{P} t \mathbf{B u}_{2}$ atom, the electron density shifts towards the $\mathrm{PCO}_{2}$ moiety; the value of the $\mathbf{B}\left(\mathrm{iPr}_{2} \mathrm{~N}\right)_{2}$ electrophilic Fukui function, $f_{\mathrm{E}}$, increases from 0.001 for 1 to 0.152 for $\mathbf{I}$ (Table S10†). Consequently, the $\mathbf{B}\left(\mathrm{iPr}_{2} \mathrm{~N}\right)_{2}$ atom becomes the electrophilic center of the molecule, facilitating the formation of the $\mathrm{B}-\mathrm{O}$ bond, and the simultaneous cleavage of the $\mathrm{P}-\mathrm{B}$ bond leads to the generation

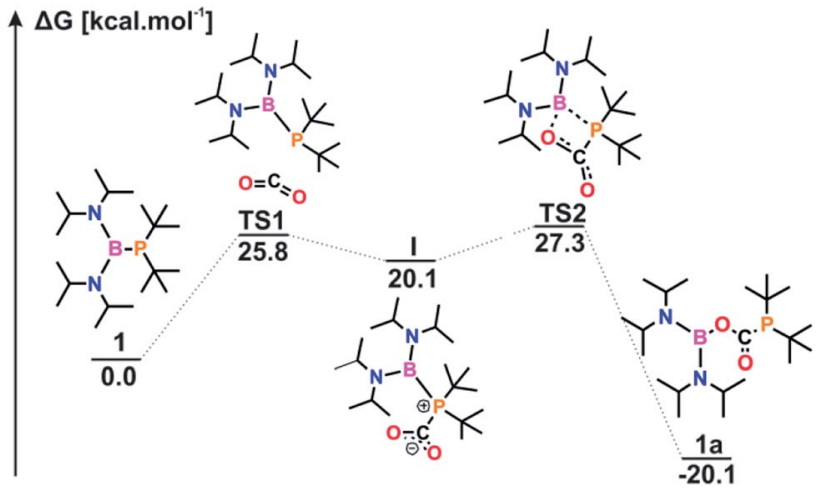

Fig. 3 The Gibbs energy profile of the formation of $1 a$ 
of 1a. Although the values of the free energies $\left(\Delta G_{298}\right)$ confirmed that in the reaction with $\mathrm{CO}_{2}$, all three systems form stable products via exergonic processes, the kinetics of these reactions are notably different (Table 1 ).

In general, as the nucleophilicity of the phosphorus atom in 1-3 decreases, the energy barrier $\Delta G^{\ddagger}$ increases. A small aberration is observed for $\mathbf{2 a} \mathbf{P} t \mathbf{B u P h}$ is less nucleophilic than $\mathbf{P} t \mathbf{B u}_{2}$ but is also less sterically hindered, and therefore, the value of $\Delta G^{\ddagger}$ is slightly lower for $2 \mathrm{a}$ (Fig. S41†). While 1 and 2 react with $\mathrm{CO}_{2}$ in an analogous manner involving the generation of adduct I, a PES scan of 3a revealed that the corresponding intermediate is not formed along the reaction path (Fig. S42 $\dagger$ ). In this case, the activation of $\mathrm{CO}_{2}$ proceeds via a single four-membered ring transition state. This path requires the simultaneous interaction of both reactive centers with $\mathrm{CO}_{2}$, which in conjunction with the $\mathbf{P P h}_{2}$ atom being the least nucleophilic, justifies the highest energy barrier and the extremely long reaction time for 3.

We found it very interesting to compare the reactivities of trivalent species containing single and double boronphosphorus bonds (Scheme 4). Stephan and coworkers revealed that phosphinoboranes $\mathrm{R}_{2} \mathrm{P}=\mathrm{B}\left(\mathrm{C}_{6} \mathrm{~F}_{5}\right)_{2}(\mathrm{R}=t \mathrm{Bu}, \mathrm{Cy})$ can activate dihydrogen ${ }^{34,37}$ (Scheme 4 , bottom left); however, we did not find any reports on the reactivity of such species towards $\mathrm{CO}_{2}$.

For this reason, we reacted a representative species, $t \mathrm{Bu}_{2} \mathrm{P}=$ $\mathrm{B}\left(\mathrm{C}_{6} \mathrm{~F}_{5}\right)_{2}{ }^{34,37}(\mathrm{~A})$, with $\mathrm{CO}_{2}$ under the same conditions as described for 1 . The monitoring of the reaction mixture by ${ }^{31} \mathrm{P}$ $\left\{{ }^{1} \mathrm{H}\right\}$ and ${ }^{11} \mathrm{~B}$ spectroscopy showed that compound $\mathbf{A}$ does not activate $\mathrm{CO}_{2}$. Furthermore, in the reaction of 1 with $\mathrm{H}_{2}$ conducted under the same conditions, the ${ }^{31} \mathrm{P}\left\{{ }^{1} \mathrm{H}\right\}$ and ${ }^{11} \mathrm{~B}$ NMR spectra revealed only signals of unreacted 1 . The differences in the reactivity of $\mathbf{1}$ and $t \mathrm{Bu}_{2} \mathrm{P}=\mathrm{B}\left(\mathrm{C}_{6} \mathrm{~F}_{5}\right)_{2}$ towards $\mathrm{H}_{2}$ and $\mathrm{CO}_{2}$ can be explained by their electronic structures. According to the

Table 1 Free energies $(\Delta G)$ and activation free energies $\left(\Delta G^{\ddagger}\right)$ for the capture of $\mathrm{CO}_{2}$ by $1-3^{a}$

\begin{tabular}{lll}
\hline Reaction & $\Delta G^{\ddagger}\left[\mathrm{kcal} \mathrm{mol}^{-1}\right]$ & $\Delta G\left[\mathrm{kcal} \mathrm{mol}^{-1}\right]$ \\
\hline 1a & 27.3 & -20.1 \\
2a & 26.4 & -17.8 \\
3a & 30.2 & -10.8 \\
${ }^{a} \omega \mathrm{B} 97 X \mathrm{D} / 6-31 \mathrm{G}+(\mathrm{d}, \mathrm{p})$. &
\end{tabular}
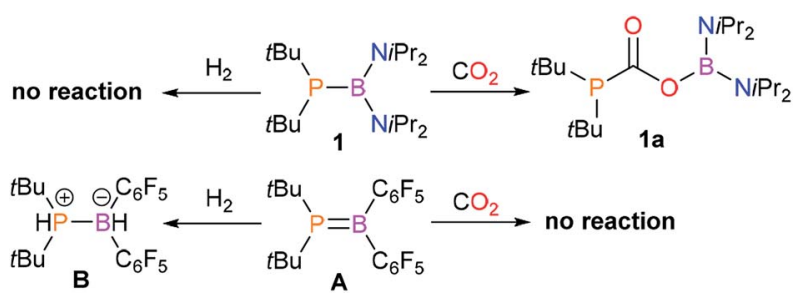

Scheme 4 Comparison of the reactivities of species possessing $\mathrm{P}-\mathrm{B}$ or $\mathrm{P}=\mathrm{B}$ bonds towards $\mathrm{H}_{2}$ and $\mathrm{CO}_{2}$. mechanism of $\mathrm{H}_{2}$ activation proposed by Stephan, the reaction starts with the addition of $\mathrm{H}_{2}(\mathrm{H}-\mathrm{H}$ bond acts as a Lewis base) to the Lewis acidic B-center of $t \mathrm{Bu}_{2} \mathrm{P}=\mathrm{B}\left(\mathrm{C}_{6} \mathrm{~F}_{5}\right)_{2} \cdot{ }^{34,37}$ In the case of $\mathbf{1}$, the Lewis acidity of boron is quenched due to the strong donation from both $\mathrm{N}$ atoms, which explains its lack of reactivity towards $\mathrm{H}_{2}$. In regard to $\mathrm{CO}_{2}$, our mechanistic study reveals that the presence of a strong nucleophilic $\mathrm{P}$ center with an accessible lone pair is crucial for the activation of electrophilic $\mathrm{CO}_{2}$. While compound 1 meets these conditions, in the case of $t \mathrm{Bu}_{2} \mathrm{P}=\mathrm{B}\left(\mathrm{C}_{6} \mathrm{~F}_{5}\right)_{2}$, the lone pair on the $\mathrm{P}$ atom is involved in a strong donor-acceptor interaction with the $\mathrm{B}$ atom, resulting in $\pi$-bonding.

\section{Conclusions}

We have synthesized a series of novel monomeric diaminophosphinoboranes which are not only effective species for functionalization of $\mathrm{CO}_{2}$ but are also promising systems for activation of other small molecules. Our studies revealed which factors are crucial for the activation of small molecules by trivalent phosphorus and boron species with direct $\mathrm{P}-\mathrm{B}$ bond and how to design effective systems of this kind. Studies on the reactivity of diaminophosphinoboranes towards a wide range of small, electrophilic molecules are currently in progress.

\section{Conflicts of interest}

There are no conflicts to declare.

\section{Acknowledgements}

R. G., N. S., and A. O. thank the National Science Centre NCN, Poland (Grant 2016/21/B/ST5/03088) for their financial support. The authors thank TASK Computational Center for access to computational resources.

\section{Notes and references}

1 F. G. Fontaine, M. A. Courtemanche, M. A. Légaré and É. Rochette, Coord. Chem. Rev., 2017, 334, 124-135.

2 D. J. Scott, M. J. Fuchter and A. E. Ashley, Chem. Soc. Rev., 2017, 46, 5689-5700.

3 L. Greb, P. Oña-Burgos, B. Schirmer, S. Grimme, D. W. Stephan and J. Paradies, Angew. Chem., Int. Ed., 2012, 51, 10164-10168.

4 D. W. Stephan, J. Am. Chem. Soc., 2015, 137, 10018-10032.

5 S. Mummadi, D. K. Unruh, J. Zhao, S. Li and C. Krempner, J. Am. Chem. Soc., 2016, 138, 3286-3289.

6 D. W. Stephan, Acc. Chem. Res., 2015, 48, 306-316.

7 E. Theuergarten, T. Bannenberg, M. D. Walter, D. Holschumacher, M. Freytag, C. G. Daniliuc, P. G. Jones and M. Tamm, Dalton Trans., 2014, 43, 1651-1662.

8 M. A. Dureen and D. W. Stephan, J. Am. Chem. Soc., 2010, 132, 13559-13568.

9 G. Ménard and D. W. Stephan, J. Am. Chem. Soc., 2010, 132, 1796-1797.

10 W. B. Tolman, Activation of Small Molecules, Wiley, 2006. 
11 F. Buß, P. Mehlmann, C. Mück-Lichtenfeld, K. Bergander and F. Dielmann, J. Am. Chem. Soc., 2016, 138, 1840-1843.

12 S. Bontemps, Coord. Chem. Rev., 2016, 308, 117-130.

13 H. Sabet-Sarvestani, M. Izadyar and H. Eshghi, J. CO2 Util., 2017, 21, 459-466.

14 D. W. Stephan and G. Erker, Chem. Sci., 2014, 5, 2625-2641.

15 M. Sajid, A. Klose, B. Birkmann, L. Liang, B. Schirmer,

T. Wiegand, H. Eckert, A. J. Lough, R. Fröhlich,

C. G. Daniliuc, S. Grimme, D. W. Stephan, G. Kehr and

G. Erker, Chem. Sci., 2013, 213-219.

16 P. A. Chase and D. W. Stephan, Angew. Chem., Int. Ed., 2008, 47, 7433-7437.

17 D. W. Stephan and G. Erker, Angew. Chem., Int. Ed., 2010, 49, 46-76.

18 G. C. Welch, R. R. S. Juan, J. D. Masuda and D. W. Stephan, Science, 2006, 314, 1124-1126.

19 T. A. Rokob, I. Bakó, A. Stirling, A. Hamza and I. Pápai, J. Am. Chem. Soc., 2013, 135, 4425-4437.

20 M. A. Courtemanche, M. A. Légaré, L. Maron and F. G. Fontaine, J. Am. Chem. Soc., 2014, 136, 10708-10717.

21 T. Mahdi and D. W. Stephan, J. Am. Chem. Soc., 2014, 136, 15809-15812.

22 R. Declercq, G. Bouhadir, D. Bourissou, M. A. Légaré, M. A. Courtemanche, K. S. Nahi, N. Bouchard, F. G. Fontaine and L. Maron, ACS Catal., 2015, 5, 2513-2520.

23 T. Wang and D. W. Stephan, Chem. Commun., 2014, 50, 7007-7010.

24 T. Privalov, Chem.-Eur. J., 2009, 15, 1825-1829.

25 W.-H. Wang, X. Feng and M. Bao, in SpringerBriefs in Molecular Science, 2018, pp. 7-42.

26 D. Chen, Y. Wang and J. Klankermayer, Angew. Chem., Int. Ed., 2010, 49, 9475-9478.

27 C. M. Mömming, E. Otten, G. Kehr, R. Fröhlich, S. Grimme, D. W. Stephan and G. Erker, Angew. Chem., Int. Ed., 2009, 48, 6643-6646.

28 F. Bertini, V. Lyaskovskyy, B. J. J. Timmer, F. J. J. de Kanter, M. Lutz, A. W. Ehlers, J. C. Slootweg and K. Lammertsma, J. Am. Chem. Soc., 2012, 134, 201-204.

29 Y. Wang, Z. H. Li and H. Wang, RSC Adv., 2018, 8, 2627126276.

30 R. T. Paine and H. Nöth, Chem. Rev., 1995, 95, 343-379.
31 J. A. Bailey and P. G. Pringle, Coord. Chem. Rev., 2015, 297298, 77-90.

32 J. A. Bailey, M. Ploeger and P. G. Pringle, Inorg. Chem., 2014, 53, 7763-7769.

33 M. Kaaz, C. Bäucker, M. Deimling, S. König, S. H. Schlindwein, J. Bender, M. Nieger and D. Gudat, Eur. J. Inorg. Chem., 2017, 2017, 4525-4532.

34 S. J. Geier, T. M. Gilbert and D. W. Stephan, Inorg. Chem., 2011, 50, 336-344.

35 P. P. Power, Angew. Chem., Int. Ed. Engl., 1990, 29, 449-460.

36 D. C. Pestana and P. P. Power, J. Am. Chem. Soc., 1991, 113, 8426-8437.

37 S. J. Geier, T. M. Gilbert and D. W. Stephan, J. Am. Chem. Soc., 2008, 130, 12632-12633.

38 E. N. Daley, C. M. Vogels, S. J. Geier, A. Decken, S. Doherty and S. A. Westcott, Angew. Chem., Int. Ed., 2015, 54, 21212125.

39 M. B. Kindervater, J. F. Binder, S. R. Baird, C. M. Vogels, S. J. Geier, C. L. B. Macdonald and S. A. Westcott, J. Organomet. Chem., 2019, 880, 378-385.

40 S. J. Geier, C. M. Vogels, N. R. Mellonie, E. N. Daley, A. Decken, S. Doherty and S. A. Westcott, Chem.-Eur. J., 2017, 23, 14485-14499.

41 S. J. Geier, J. H. W. Lafortune, D. Zhu, S. C. Kosnik, C. L. B. Macdonald, D. W. Stephan and S. A. Westcott, Dalton Trans., 2017, 46, 10876-10885.

42 J. Lafortune, Z.-W. Qu, K. Bamford, A. Trofimova, S. Westcott and D. W. Stephan, Chem.-A Eur. J., 2019, DOI: 10.1002/ chem.201903407.

43 N. Szynkiewicz, Ł. Ponikiewski and R. Grubba, Dalton Trans., 2018, 47, 16885-16894.

44 N. Szynkiewicz, Ł. Ponikiewski and R. Grubba, Chem. Commun., 2019, 55, 2928-2931.

45 P. Pyykkö and M. Atsumi, Chem.-Eur. J., 2009, 15, 186-197.

46 P. Pyykkö and M. Atsumi, Chem.-Eur. J., 2009, 15, 1277012779.

47 F. H. Allen, D. G. Watson, L. Brammer, A. G. Orpen and R. Taylor, in International Tables for Crystallography, ed. T. Hahn, International Union of Crystallography, Chester, England, 2006, vol. A, pp. 790-811. 